\title{
Post-endoscopic retrograde cholangiopancreatography pancreatitis prevention using topical epinephrine: systematic review and meta-analysis
}

두(1) $(9$

\author{
Authors \\ Umair Iqbal ${ }^{1}$, Osama Siddique², Harshit S. Khara ${ }^{3}$, Muhammad Ali Khan ${ }^{4}$, Khwaja Fahad Haq ${ }^{5}$, Mohammad Arsalan \\ Siddiqui ${ }^{6}$, Shantanu Solanki ${ }^{7}$, Tobias E. Zuchelli ${ }^{6}$, Matthew Joshua Shellenberger ${ }^{3}$, John W. Birk ${ }^{2}$
}

Institutions

1 Geisinger Medical Center - Department of Gastroenterology and Hepatology, Danville, Pennsylvania, United States

2 University of Connecticut Health Center Gastroenterology and Hepatology, Farmington, Connecticut, United States

3 Geisinger Medical Center - Department of Gastroenterology and Nutrition, Danville, Pennsylvania, United States

4 University of Alabama at Birmingham Gastroenterology and Hepatology, Birmingham, Alabama, United States

5 Henry Ford Hospital - Gastroenterology, Detroit, Michigan, United States

6 Henry Ford Hospital - Gastroenterology and Hepatology, Detroit, Michigan, United States

7 Department of Internal Medicine - Guthrie Robert Packer Hospital, Sayre, Pennsylvania, United States

submitted 20.11.2019

accepted after revision $\quad 21.4 .2020$

\section{Bibliography}

DOI https://doi.org/10.1055/a-1190-3777 |

Endoscopy International Open 2020; 08: E1061-E1067

(c) Georg Thieme Verlag KG Stuttgart · New York eISSN 2196-9736

\section{Corresponding author}

Umair Iqbal, MD, Clinical Assistant Professor, Department of Internal Medicine, Geisinger Medical Center, Danville, PA, 17822, USA

Fax: +1-570-214-9519

umairiqbal_dmc@hotmail.com

\section{ABSTRACT}

Background and study aims Post-endoscopic retrograde cholangiopancreatography pancreatitis (PEP) is a common complication of endoscopic retrograde cholangiopancreatography (ERCP). Multiple drugs and techniques have been studied for the prevention of PEP. Topical epinephrine has shown mixed results and is still not widely accepted as an alternative for prevention of PEP. We performed a systematic review and meta-analysis to evaluate the efficacy of topical epinephrine in preventing PEP.

Methods A comprehensive literature review was conducted by searching Cochrane library database, Embase and PubMed up to August 2019, to identify all studies that evaluated use of topical epinephrine alone or in conjunction with other agents for prevention of PEP. Outcomes included prevention of PEP with use of topical epinephrine and evaluation of whether addiing epinephrine provides any additional benefit in preventing PEP. All analysis was conducted using Revman 5.3.

Results Eight studies, including six randomized controlled trials and two observational studies with 4123 patients, were included in the meta-analysis. Overall, there was no difference in incidence of PEP in patients who underwent ERCP and were treated with epinephrine spray versus those who were not, $\mathrm{RR}=0.63(\mathrm{Cl} 0.32-1.24)$ with heterogeneity ( $12=72 \%)$. However, on a subgroup analysis, topical epinephrine significantly decreases the risk of PEP when compared to placebo alone (means no intervention was done including no rectal indomethacin)., $R R=0.32(0.18-0.57)$. In another subgroup analysis, there was no statistically significant difference in using topical epinephrine along with rectal indomethacin in preventing PEP compared to rectal indomethacin alone RR=0.87 (0.46-1.64).

Conclusion Topical epinephrine does not provide any additional benefit in preventing PEP when used in conjunction with rectal indomethacin. In subgroup analysis, topical epinephrine appeared to decrease risk of PEP in the absence of rectal indomethacin, and could be considered when rectal indomethacin is unavailable or if there is a contraindication to its use. 


\section{Introduction}

Post-endoscopic retrograde cholangiopancreatography pancreatitis (PEP) is the most common complication of endoscopic retrograde cholangiopancreatography pancreatitis (ERCP) and as defined by Cotton et al., it is characterized by two of the following three findings; abdominal pain, elevation of pancreatic enzymes three times the upper limit, and/or radiographic findings of pancreatitis [1]. Incidence of PEP is around $5 \%$ to $10 \%$ with severe pancreatitis comprising $0.3 \%$ to $0.5 \%$ of cases [24]. Mortality associated with PEP is about $0.2 \%$ [3]. Risk factors for PEP include female sex, younger patient age, sphincter of Oddi dysfunction, normal-sized common bile duct, difficult or prolonged cannulation, ERCP requiring balloon dilation of an intact sphincter, and pancreatic sphincterotomy [2, 5, 6]. Ampullary trauma from manipulation or prolonged cannulation plays a role in PEP. Procedural techniques such as guidewire cannulation, needle-knife access, and early precut can reduce ampullary injury and thus aid in preventing PEP, though they may come with their own risk of PEP $[7,8]$. In a recent systematic review including 25 randomized controlled trials (RCTs), incidence of PEP in patients with common bile duct stones who underwent ERCP was comparable between endoscopic papillary balloon dilation, endoscopic sphincterotomy (ES), and the combination of large balloon dilation and endoscopic sphincterotomy [9]. In another systematic review, evaluating the safety of different modes of electrical current during biliary sphincterotomy revealed that pure cut carries a lower risk of PEP while the monopolar mode is associated with a higher risk of PEP [10]. There is no difference in PEP with use of carbon dioxide insufflation compared to ambient air insufflation [11]. In patients with repeated pancreatic duct (PD) cannulation and contrast injection, a prophylactic PD stent has been shown to reduce PEP $[12,13]$.

Besides endoscopic procedural techniques, many pharmacological agents have been studied for prophylaxis of PEP [14]. Rectal nonsteroidal anti-inflammatory drugs (NSAIDs) have been shown to decrease incidence of PEP and the American Society for Gastrointestinal Endoscopy recommends use of rectal indomethacin or diclofenac immediately before or after the ERCP for the prevention of PEP [15-17]. In a recent meta-analysis of 21 RCTs, including 6584 patients, administration of rectal diclofenac and indomethacin significantly reduced risk of developing mild PEP [17].

Topical epinephrine has recently been studied for prevention of PEP and theoretically should work similarly as a PD stent. Topical epinephrine sprayed on the ampulla can reduce edema by arteriolar vasoconstriction and therefore improve pancreatic outflow [18]. Evidence regarding use of topical epinephrine in prevention of PEP is inconsistent, with some studies favoring their use while other studies did not show any benefit. Compounding this question is concurrent use of topical epinephrine with rectal NSAIDS [19-21]. We, therefore, conducted a systematic review and meta-analysis to delineate if topical epinephrine is useful in the prevention of PEP.

\section{Materials and methods}

\section{Information sources and search strategy}

A systematic literature search was conducted of the Cochrane library database, Embase and PubMed, from Inception to August 8, 2019 to identify all studies that evaluated the role of topical epinephrine in prevention of PEP. The systematic literature review was independently conducted by two investigators (U. lqbal and M. Siddiqui) using search terms as follows: "Epinephrine" [Mesh] OR epinephrine [tiab] OR adrenaline [tiab] AND "Cholangiopancreatography, Endoscopic Retrograde" [Mesh] OR "endoscopic retrograde cholangiopancreatography" [tiab] OR ERCP [tiab] AND "Pancreatitis" [Mesh] OR pancreatitis [tiab] OR Pancreatitides [tiab]. Details of the exact search terms are listed in Appendix. A manual search for further relevant articles was also performed using references from the included articles. We did not apply any language limitations for inclusion of studies. Our study was conducted in agreement with the preferred reporting items for systematic reviews and meta-analysis (PRISMA) statement [22]. We have registered our systematic review in the PROSPERO international database with registration number CRD42020147575.

\section{Selection criteria}

Eligible studies were required to be RCTs or observational studies that evaluated use of topical epinephrine for prevention of PEP. If a study was presented as both abstract and later published, we included the fully published article in our meta-analysis to avoid duplication. Sample size of a study did not restrict its inclusion to the systematic review. We excluded individual case reports or case series from our systematic review. The Newcastle-Ottawa quality assessment scale was used to evaluate the quality of observational studies in three areas: recruitment of cases and controls, comparability of the two groups and outcome of interest of the cohort study. The methodological quality of the RCTs included in the analysis was measured using the Jadad scoring system from 0 to 5 [23]. Results of the methodological quality assessment did not impact the eligibility of the studies to be included in the meta-analysis.

\section{Data extraction}

A structured data collection form was used to extract the following data from each study: title of the study, publication year, name of the first author, country where the study was performed, number of participants, characteristics of participants, use of topical epinephrine, use of any other agents for prevention of PEP (rectal indomethacin) and outcome measurement (incidence of PEP, and severe pancreatitis). To ensure accuracy, data extraction was independently performed by two investigators (U IQBAL and O Siddique) and was reviewed by the third investigator (K Haq). Any disagreement was resolved by mutual consensus.

\section{Statistical analysis}

Statistical analysis was performed using RevMan 5.3 software (Cochrane Collaboration, London, United Kingdom). For the main outcome (incidence of PEP), incidence of PEP in the epine- 


\begin{tabular}{|c|c|}
\hline \multicolumn{2}{|c|}{$\begin{array}{l}\text { Records identified through searching } \\
(n=109)\end{array}$} \\
\hline \multicolumn{2}{|l|}{$\downarrow$} \\
\hline \multicolumn{2}{|c|}{$\begin{array}{l}\text { Records after duplicates removed } \\
(n=37)\end{array}$} \\
\hline$\downarrow$ & \\
\hline $\begin{array}{l}\text { Records screened } \\
(n=72)\end{array}$ & $\begin{array}{l}\text { Records excluded } \\
(n=57)\end{array}$ \\
\hline & \\
\hline $\begin{array}{l}\text { Full-text articles } \\
\text { assessed for eligibility } \\
(n=15)\end{array}$ & $\begin{array}{l}\text { Full-text articles } \\
\text { excluded, } \\
(n=7)\end{array}$ \\
\hline \multicolumn{2}{|l|}{$\downarrow$} \\
\hline \multicolumn{2}{|c|}{$\begin{array}{l}\text { Studies included in qualitative synthesis } \\
(n=8)\end{array}$} \\
\hline \\
\hline \multicolumn{2}{|c|}{$\begin{array}{l}\text { Studies included in quantitative synthesis } \\
\text { (meta-analysis) } \\
(\mathrm{n}=8)\end{array}$} \\
\hline
\end{tabular}

- Fig. 1 Literature review process.

phrine group compared with patients who did not receive epinephrine was determined using the Mantel-Haenszel OR. An overall OR of less than 1 for this outcome indicated that the odds of PEP were lower in the treatment group than in the control group.A random-effects model was uszed for this meta-analysis, with point estimates, variance, and weights for each study based on the size of the study and the number of events. $P<0.05$ was considered statistically significant. Heterogeneity was assessed using the 12 index. A value of 12 of $0 \%$ to $25 \%$ represented insignificant heterogeneity, $26 \%$ to $50 \%$ represented low heterogeneity, $51 \%$ to $75 \%$ represented moderate heterogeneity, and $>75 \%$ represented high heterogeneity [24]. The secondary outcome was to evaluate the incidence of severe pancreatitis.

\section{Results}

Initial search revealed 109 articles, of which eight studies, including six RCTs and two observational studies with $4123 \mathrm{pa}-$ tients were included in this systematic review and meta-analysis [19-21, 25-29]. - Fig. 1 shows the systematic search used in the study. It is important to note that our overall results included two types of studies: some that which evaluated both topical epinephrine and rectal indomethacin therapy together and some studies that compared topical epinephrine versus placebo therapy. Five RCTs were of good quality while one was of fair quality. Both the observational studies were of good quality. Baseline characteristics of the included studies are shown in - Table 1.

\section{Topical epinephrine overall}

Of 4123 patients, 1839 received topical epinephrine alone or in conjunction with rectal indomethacin, and 1997 did not receive topical epinephrine. Overall, there was no significant difference in incidence of PEP in patients who were treated with topical epinephrine compared to patients who did not receive topical epinephrine during the ERCP procedure $R R=0.63(\mathrm{Cl} 0.32-$ 1.24 ) with heterogeneity $(I 2=72 \%$ ) ( Fig. 2 ). A subgroup analysis evaluating RCTs and observational studies was done separately. There was no difference in incidence of PEP in either the RCTs or the observational studies with $R R=0.71(0.37-$ $1.40)$ and $O R=0.16(0.02-1.29)$ for RCTs and observational studies, respectively ( $\triangleright$ Fig. 2 ). There was also no significant difference in risk of severe pancreatitis with use of topical epinephrine $R R=1.47$ (0.59-3.64).

\section{Rectal indomethacin with or without topical epinephrine}

We also performed a subgroup analysis to evaluate whether adding topical epinephrine to rectal indomethacin would further reduce incidence of PEP. Three studies compared risk of PEP in patients undergoing ERCP who received rectal indomethacin alone or rectal indomethacin and epinephrine. A total of 1132 patients received rectal indomethacin alone and 1111 patients received rectal indomethacin plus topical epinephrine. There was no statistically significant difference in using topical epinephrine along with rectal indomethacin in preventing PEP compared to rectal indomethacin alone $R R=0.87(0.46-1.64)$ with heterogeneity $(12=61 \%)(\triangleright$ Fig. 3$)$.

\section{Topical epinephrine vs. placebo (saline spray or no-intervention)}

Five studies compared incidence of PEP in patients who underwent ERCP and received epinephrine spray or placebo (saline spray or no-intervention). 864 patients received epinephrine spray during ERCP, and 979 patients received a placebo (means no intervention was done including no rectal indomethacin). Fourteen patients (1.6\%) developed PEP in the epinephrine group compared to 49 patients $(5.0 \%)$ in the placebo group. Topical epinephrine significantly decreased risk of PEP when compared to placebo, pooled $R R=0.32(0.18-0.57)$ with no heterogeneity ( $\triangleright \mathbf{F i g} .4)$. There was no publication bias as evaluated by the funnel plot diagram ( $\triangleright$ Fig. 5).

\section{Discussion}

We performed this comprehensive systematic review and meta-analysis to evaluate the role of topical epinephrine in prevention of PEP. Hatami et al., in a randomized double-blind controlled trial that included patients at high risk of PEP, observed that use of epinephrine alone or in conjunction with rectal indomethacin is effective in reducing incidence of PEP [20]. In that study, $8.8 \%$ of patients in the indomethacin alone group developed PEP compared to $0.8 \%$ of patients who received epinephrine alone or in combination with rectal indomethacin. Similar results were seen in a randomized trial of 370 ERCP patients 
- Table1 Baseline characteristics of included studies.

\begin{tabular}{|c|c|c|c|c|c|c|}
\hline $\begin{array}{l}\text { Study author } \\
\text { Year } \\
\text { Country }\end{array}$ & $\begin{array}{l}\text { Study } \\
\text { Design }\end{array}$ & $\begin{array}{l}\text { Sample } \\
\text { Size }\end{array}$ & $\begin{array}{l}\text { Quality of } \\
\text { the study }\end{array}$ & Treatment group & Control group & $\begin{array}{l}\text { Epinephrine } \\
\text { concentration }\end{array}$ \\
\hline $\begin{array}{l}\text { Kamal et al. } \\
2018 \\
\text { USA [19] }\end{array}$ & $\mathrm{RCT}$ & $N=960$ & Jadad $=5$ & $\begin{array}{l}\text { Indomethacin + } \\
\text { epinephrine }\end{array}$ & Indomethacin + saline spray & $0.02 \%$ \\
\hline $\begin{array}{l}\text { Hatami et al. } \\
2018 \\
\text { Iran [20] }\end{array}$ & $\mathrm{RCT}$ & $N=192$ & Jadad $=5$ & $\begin{array}{l}\text { Indomethacin + } \\
\text { epinephrine }\end{array}$ & $\begin{array}{l}\text { Indomethacin + saline spray or } \\
\text { epinephrine spray + placebo sup- } \\
\text { pository }\end{array}$ & $0.01 \%$ \\
\hline $\begin{array}{l}\text { Xu et al. } \\
2011 \\
\text { China [21] }\end{array}$ & $\mathrm{RCT}$ & $N=941$ & Jadad $=5$ & Epinephrine spray & Saline spray & $0.02 \%$ \\
\hline $\begin{array}{l}\text { Luo et al. } \\
\text { 2019, China } \\
{[25]}\end{array}$ & $\mathrm{RCT}$ & $N=1158$ & Jadad $=5$ & $\begin{array}{l}\text { Indomethacin + } \\
\text { epinephrine }\end{array}$ & Indomethacin + saline spray & $0.02 \%$ \\
\hline $\begin{array}{l}\text { Nakaji et al. } \\
2009 \\
\text { Japan [26] }\end{array}$ & RCS & $N=114$ & Good quality & Epinephrine spray & No treatment & $0.05 \%$ \\
\hline $\begin{array}{l}\text { Matsushita et al. } \\
2008 \\
\text { Japan [27] }\end{array}$ & $\mathrm{RCT}$ & $N=370$ & Jadad $=4$ & Epinephrine spray & Saline spray & $0.02 \%$ \\
\hline $\begin{array}{l}\text { Ohashi et al. } \\
2001 \\
\text { Japan [28] }\end{array}$ & RCS & $N=173$ & Good quality & Epinephrine spray & No treatment & $0.0001 \%$ \\
\hline $\begin{array}{l}\text { Chaitanya et al. } \\
2016 \\
\text { India [29] }\end{array}$ & $\mathrm{RCT}$ & $N=217$ & Jadad $=2$ & $\begin{array}{l}\text { Indomethacin or } \\
\text { epinephrine }\end{array}$ & No treatment & $0.02 \%$ \\
\hline
\end{tabular}

by Matsushita [27]. In that study, PEP developed in four of 185 patients $(2 \%)$ in the control group who received saline spray (placebo) compared to none of 185 patients (0\%) who received epinephrine. $\mathrm{Xu}$ et al. in a randomized trial also revealed that use of epinephrine is associated with lower incidence of PEP ( $1.95 \%$ in epinephrine group vs. $6.45 \%$ in control group) [21].

Although some of the above studies have shown beneficial outcomes with use of topical epinephrine in preventing PEP, some have failed to show any significant difference in incidence of PEP. Luo et al., in a randomized double-blind multicenter trial, which included 1158 patients, found a higher incidence of PEP in patients who received epinephrine and rectal indomethacin compared to patients who received rectal indomethacin alone (8.5\% vs. 5.3\%) [25]. Similarly, Kamal et al. in a multicenter double-blinded randomized trial, showed no significant difference in incidence of PEP in patients who received indomethacin alone compared to a combination of indomethacin and epinephrine $(6.4 \%$ in indomethacin group vs $6.7 \%$ in combination group) [19].Considering current evidence and results of our meta-analysis, we do not recommend use of topical epinephrine in addition to rectal indomethacin for the prevention of PEP.

Our meta-analysis showed the benefit of epinephrine spray alone over no intervention in preventing PEP. Lack of procedural manipulation need and cost-benefit of preventing PEP makes topical epinephrine a reasonable approach in comparison to no intervention or even pancreatic duct stenting in certain circumstances. Topical epinephrine $0.1 \mathrm{mg} / \mathrm{ml}(1: 10,000)$ is easily available in anesthesiology carts, making it relatively more accessible when needed during a procedure. Topical epinephrine usage instead of rectal nonsteroidal anti-inflammatory drugs (NSAIDs) can be considered in patients having absolute contraindications to NSAIDs such as allergies to NSAIDs, end-stage kidney disease, or who have had proctocolectomy. It may also be considered as a suitable alternative to prophylactic pancreatic stenting in specific circumstances; but evidence is lacking currently. Topical epinephrine, however, may be advantageous over pancreatic duct (PD) stenting for numerous reasons. PD stenting can be technically challenging, can prolong papillae manipulation, and PD stents at times need to be removed by a repeat procedure or can even migrate into the PD. In addition, topical epinephrine is much more cost-effective then a PD stent. Notably, both methods have efficacy alone, yet neither has been shown to improve indomethacin efficacy $[19,30]$.

The systematic literature search in our study was comprehensive, and a majority of the studies were good-quality RCTs with a reasonable sample size; nevertheless, we do acknowledge that our paper has some limitations and results that 


\begin{tabular}{|c|c|c|c|c|c|c|c|c|c|c|}
\hline Study or subgroup & \multicolumn{2}{|c|}{ Epinephrine } & \multicolumn{3}{|c|}{ No Epinephrine } & $\begin{array}{c}\text { Risk ratio } \\
\text { M-H, Random, } 95 \% \mathrm{CI}\end{array}$ & \multicolumn{4}{|c|}{$\begin{array}{c}\text { Risk ratio } \\
\text { M-H, Random, } 95 \% \mathrm{Cl}\end{array}$} \\
\hline \multicolumn{11}{|c|}{ 1.6.1 Randomized controlled trials } \\
\hline Chaitanya, 2016 & 4 & 74 & 9 & 142 & $14.8 \%$ & $0.85[0.27,2.68]$ & & & & \\
\hline Hatami, 2018 & 1 & 66 & 6 & 126 & $7.3 \%$ & $0.32[0.04,2.59]$ & & & & \\
\hline Kamal, 2019 & 32 & 477 & 31 & 482 & $22.9 \%$ & $1.04[0.65,1.68]$ & & & - & \\
\hline Luo, 2019 & 49 & 576 & 31 & 582 & $23.4 \%$ & $1.60[1.03,2.47]$ & & & $\rightarrow-$ & \\
\hline Matsushita 2009 & 0 & 185 & 4 & 185 & $4.4 \%$ & $0.11[0.01,2.05]$ & 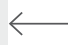 & & & \\
\hline Xu, 2011 & 9 & 461 & 31 & 480 & $19.8 \%$ & $0.30[0.15,0.63]$ & & $\longrightarrow$ & & \\
\hline Subtotal $(95 \% \mathrm{Cl})$ & & 1839 & & 1997 & $92.6 \%$ & $0.71[0.37,1.40]$ & & & - & \\
\hline Total events & 95 & & 112 & & & & & & & \\
\hline \multicolumn{11}{|c|}{ Heterogeneity: $\mathrm{Tau}^{2}=0.41 ; \mathrm{Chi}^{2}=18.42, \mathrm{df}=5(P=0.002) ; \mathrm{I}^{2}=73 \%$} \\
\hline \multicolumn{11}{|c|}{ Test for overall effect: $Z=0.98(P=0.33)$} \\
\hline \multicolumn{11}{|c|}{ 1.6.2 Observational studies } \\
\hline Nakaji, 2009 & 0 & 63 & 0 & 51 & & Not estimable & & & & \\
\hline Ohashi, 2001 & 1 & 81 & 7 & 92 & $7.4 \%$ & $0.16[0.02,1.29]$ & & & - & \\
\hline Subtotal $(95 \% \mathrm{Cl})$ & & 144 & & 143 & $7.4 \%$ & $0.16[0.02,1.28]$ & & - & & \\
\hline Total events & 1 & & 7 & & & & & & & \\
\hline \multicolumn{11}{|c|}{ Heterogeneity: not applicable } \\
\hline \multicolumn{11}{|c|}{ Test for overall effect: $Z=1.72(P=0.09)$} \\
\hline Total $(95 \% \mathrm{Cl})$ & & 1983 & & 2140 & $100.0 \%$ & $0.63[0.32,1.24]$ & & & & \\
\hline Total events & 96 & & 119 & & & & 0.01 & 0.1 & 10 & 100 \\
\hline \multicolumn{11}{|c|}{ Heterogeneity: $\operatorname{Tau}^{2}=0.45 ; \mathrm{Chi}^{2}=21.40, \mathrm{df}=6(P=0.002) ; I^{2}=72 \%$} \\
\hline \multicolumn{11}{|c|}{ Test for overall effect: $Z=1.34(P=0.18)$} \\
\hline Test for subgroup dif & ferences & $\mathrm{Chi}^{2}=$ & $1.78, \mathrm{cf}=$ & $1(P=$ & $0.18) .1^{2}=$ & $43.8 \%$ & & & & \\
\hline
\end{tabular}

- Fig. 2 Epinephrine versus no epinephrine.

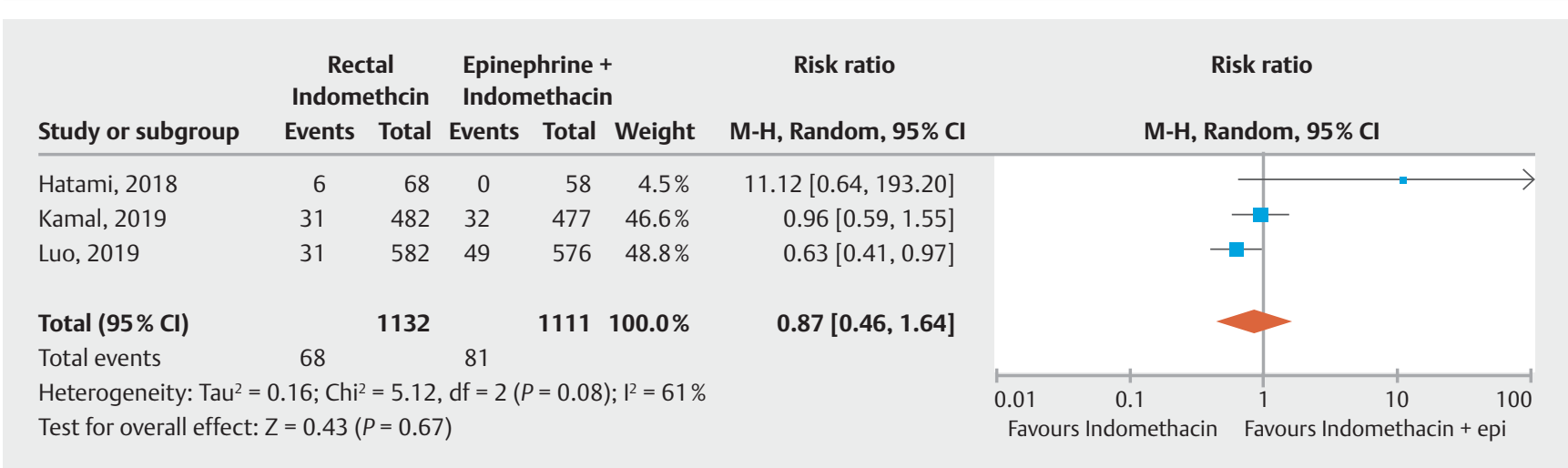

- Fig. 3 Rectal indomethacin plus topical epinephrine vs rectal indomethacin alone.

should be interpreted with caution. One of the studies was in abstract form and has not been fully published [29]. Two of the included studies were observational, which might have introduced bias in the study results $[26,28]$. Some of our analyses were limited by significant heterogeneity, therefore, we used a random effects model for meta-analysis. Further to explore heterogeneity, we did subgroup analysis by separately analyzing RCTs and observational studies and found no differences ( Fig. 2). Other factors that impact risk of PEP, including intravenous hydration, procedural expertise, and procedural technique modification are not consistently reported in studies and might confound our study results $[15,31]$.

\section{Conclusion}

In summary, topical epinephrine does not provide any additional advantage in combination with rectal indomethacin in prevention of PEP in patients who have undergone ERCP. However, topical epinephrine alone is associated with lower risk of PEP compared to placebo and can be considered if rectal indomethacin is unavailable or there is any contraindication to its use. Future studies comparing topical epinephrine versus PD stenting can be considered to evaluate whether topical epinephrine provides a similar advantage in decreasing PEP as compared to PD stenting. 


\begin{tabular}{|c|c|c|c|c|c|c|c|c|c|c|}
\hline \multirow{3}{*}{$\begin{array}{l}\text { Study or subgroup } \\
\text { Chaitanya, } 2016\end{array}$} & \multicolumn{2}{|c|}{ Epinephrine spray } & \multicolumn{3}{|c|}{ No-intervention } & \multirow{2}{*}{$\begin{array}{c}\text { Risk ratio } \\
\text { M-H, Random, } 95 \% \mathrm{Cl}\end{array}$} & \multirow{2}{*}{\multicolumn{4}{|c|}{$\begin{array}{c}\text { Risk ratio } \\
\text { M-H, Random, } 95 \% \mathrm{Cl}\end{array}$}} \\
\hline & Events & Total & Events & Total & Weight & & & & & \\
\hline & 4 & 74 & 7 & 71 & $24.3 \%$ & $0.55[0.17,1.79]$ & & $\longrightarrow-$ & - & \\
\hline Matsushita, 2009 & 0 & 185 & 4 & 185 & $4.0 \%$ & $0.11[0.01,2.05]$ & & & & \\
\hline Nakaji, 2008 & 0 & 63 & 0 & 51 & & Not estimable & & & & \\
\hline Ohashi, 2001 & 1 & 81 & 7 & 92 & $7.9 \%$ & $0.16[0.02,1.29]$ & & & - & \\
\hline Xu, 2011 & 9 & 461 & 31 & 480 & $63.8 \%$ & $0.30[0.15,0.63]$ & & -1 & & \\
\hline Total $(95 \% \mathrm{Cl})$ & & 864 & & 879 & $100.0 \%$ & $0.32[0.18,0.57]$ & & & & \\
\hline Total events & 14 & & 49 & & & & & & & \\
\hline \multicolumn{7}{|c|}{$\begin{array}{l}\text { Heterogeneity: } \mathrm{Tau}^{2}=0.00 ; \mathrm{Chi}^{2}=1.77, \mathrm{df}=3(P=0.62) ; \mathrm{I}^{2}=0 \% \\
\text { Test for overall effect: } \mathrm{Z}=3.83(P=0.0001)\end{array}$} & 0.01 & $\begin{array}{l}0.1 \\
\text { Favours Epinephrine }\end{array}$ & 1 Favours Placebo & 100 \\
\hline
\end{tabular}

Fig. 4 Topical epinephrine versus placebo.

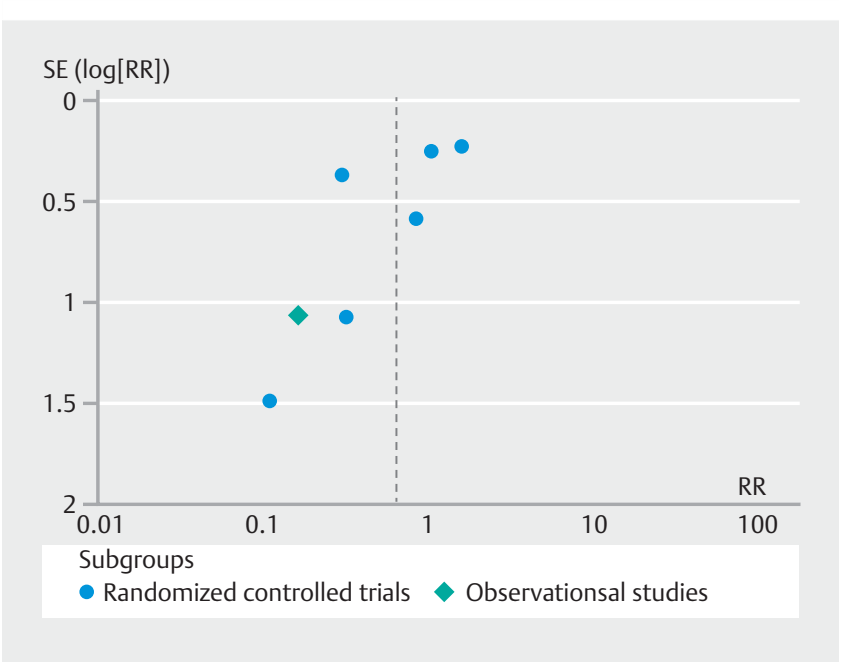

- Fig. 5 Funnel plot diagram.

\section{Acknowledgements}

The authors acknowledge, Matthew Roslund, Educational Technology Consultant, Bassett Healthcare Network

\section{Competing interests}

The authors declare that they have no conflict of interest.

\section{References}

[1] Cotton PB, Lehman G, Vennes ] et al. Endoscopic sphincterotomy complications and their management: an attempt at consensus. Gastrointest Endosc 1991; 37: 383-393

[2] Freeman ML, Nelson DB, Sherman S et al. Complications of endoscopic biliary sphincterotomy. N Engl J Med 1996; 335: 909-918

[3] Kochar B, Akshintala VS, Afghani E et al. Incidence, severity, and mortality of post-ERCP pancreatitis: a systematic review by using randomized, controlled trials. Gastrointest Endosc 2015; 81: 143149.e9
[4] Wang P, Li Z-S, Liu F et al. Risk factors for ERCP-related complications: a prospective multicenter study. Am J Gastroenterol 2009; 104: 3140

[5] Loperfido S, Angelini G, Benedetti G et al. Major early complications from diagnostic and therapeutic ERCP: a prospective multicenter study. Gastrointest Endosc 1998; 48: 1-10

[6] Yaghoobi M, Pauls Q, Durkalski V et al. Incidence and predictors of post-ERCP pancreatitis in patients with suspected sphincter of Oddi dysfunction undergoing biliary or dual sphincterotomy: results from the EPISOD prospective multicenter randomized sham-controlled study. Endoscopy 2015; 47: 884-890

[7] Lella F, Bagnolo F, Colombo E et al. A simple way of avoiding postERCP pancreatitis. Gastrointest Endosc 2004; 59: 830-834

[8] Sundaralingam P, Masson P, Bourke M]. Early precut sphincterotomy does not increase risk during endoscopic retrograde cholangiopancreatography in patients with difficult biliary access: a meta-analysis of randomized controlled trials. Clin Gastroenterol Hepatol 2015; 13: 1722-1729.e2

[9] Matsubayashi CO, Ribeiro IB, de Moura DTH et al. Is endoscopic balloon dilation still associated with higher rates of pancreatitis? a systematic review and meta-analysis Pancreas 2020; 49: 158-174

[10] Funari MP, Ribeiro IB, de Moura DTH et al. Adverse events after biliary sphincterotomy: Does the electric current mode make a difference? A systematic review and meta-analysis of randomized controlled trials Clin Res Hepatol Gastroenterol 2020: doi:10.1016/j.clinre.2019.12. 009

[11] Passos ML, Ribeiro IB, de Moura DTH et al. Efficacy and safety of carbon dioxide insufflation versus air insufflation during endoscopic retrograde cholangiopancreatography in randomized controlled trials: a systematic review and meta-analysis. Endosc Int Open 2019; 7: E487-497

[12] Freeman ML, Guda NM. Prevention of post-ERCP pancreatitis: a comprehensive review. Gastrointest Endosc 2004; 59: 845-864

[13] Mazaki T, Mado K, Masuda H et al. Prophylactic pancreatic stent placement and post-ERCP pancreatitis: an updated meta-analysis. J Gastroenterol 2014; 49: 343-355

[14] Hauser G, Milosevic M, Stimac D et al. Preventing post-endoscopic retrograde cholangiopancreatography pancreatitis: what can be done? World J Gastroenterol 2015; 21: 1069-1080

[15] Chandrasekhara V, Khashab MA, Muthusamy VR. ASGE Standards of Practice Committee. et al. Adverse events associated with ERCP. Gastrointest Endosc 2017; 85: 32-47

[16] Dumonceau J-M, Andriulli A, Elmunzer B] et al. Prophylaxis of postERCP pancreatitis: European Society of Gastrointestinal Endoscopy (ESGE) Guideline - updated June 2014. Endoscopy 2014; 46: 799-815 
[17] Serrano JPR, de Moura DTH, Bernardo WM et al. Nonsteroidal antiinflammatory drugs versus placebo for post-endoscopic retrograde cholangiopancreatography pancreatitis: a systematic review and meta-analysis. Endosc Int Open 2019; 7: E477-486

[18] Igawa M, Miyaoka M, Saitoh T. Influence of topical epinephrine application on microcirculatory disturbance in subjects with ulcerative colitis evaluated by laser Doppler flowmetry and transmission electron microscopy. Digest Endosc 2000; 12: 126-130

[19] Kamal A, Akshintala VS, Talukdar R et al. A randomized trial of topical epinephrine and rectal indomethacin for preventing post-endoscopic retrograde cholangiopancreatography pancreatitis in high-risk patients. Am J Gastroenterol 2019; 114: 339-347

[20] Hatami B, Kashfi SMH, Abbasinazari M et al. Epinephrine in the prevention of post-endoscopic retrograde cholangiopancreatography pancreatitis: a preliminary study. Case Rep Gastroenterol 2018; 12: $125-136$

[21] Xu LH, Qian JB, Gu LG et al. Prevention of post-endoscopic retrograde cholangiopancreatography pancreatitis by epinephrine sprayed on the papilla. J Gastroenterol Hepatol 2011; 26: 1139-1144

[22] Moher D, Liberati A, Tetzlaff J et al. Preferred reporting items for systematic reviews and meta-analyses: the PRISMA statement. PLoS Med 2009; 6: e1000097

[23] Jadad AR, Moore RA, Carroll D et al. Assessing the quality of reports of randomized clinical trials: is blinding necessary? Control Clin Trials 1996; 17: 1-12

[24] Higgins JPT, Thompson SG, Deeks J] et al. Measuring inconsistency in meta-analyses. BMJ 2003; 327: 557-560
[25] Luo H, Wang X, Zhang R et al. Rectal indomethacin and spraying of duodenal papilla with epinephrine increases risk of pancreatitis following endoscopic retrograde cholangiopancreatography. Clin Gastroenterol Hepatol 2019; 17: 1597-1606.e5

[26] Nakaji K, Suzumura S, Nakae Y et al. Effects in the control of edema of the papilla of Vater by epinephrine saline irrigation after endoscopic retrograde cholangiopancreatography in an endoscopy center in Japan, 2003 to 2007: exploratory retrospective analysis to evaluate the characteristics of eligible patients with a focus on serum amylase levels. Intern Med 2009; 48: 945-952

[27] Matsushita M, Takakuwa H, Shimeno N et al. Epinephrine sprayed on the papilla for prevention of post-ERCP pancreatitis. J Gastroenterol 2009; 44: 71-75

[28] Ohashi A, Tamada K, Tomiyama T et al. Epinephrine irrigation for the prevention of pancreatic damage after endoscopic balloon sphincteroplasty. J Gastroenterol Hepatol 2001; 16: 568-571

[29] Chaitanya K, Murali Krishna P, Repana K et al. Efficacy of rectal indomethacin versus papillary epinephrine spray in prevention of postERCP pancreatitis. Indian J Gastroenterol 2016; 35: A93

[30] Elmunzer B], Higgins PDR, Saini SD et al. Does rectal indomethacin eliminate the need for prophylactic pancreatic stent placement in patients undergoing high-risk ERCP? Post hoc efficacy and cost-benefit analyses using prospective clinical trial data Am J Gastroenterol 2013; 108: 410-415

[31] Park C-H, Paik WH, Park ET et al. Aggressive intravenous hydration with lactated Ringer's solution for prevention of post-ERCP pancreatitis: a prospective randomized multicenter clinical trial. Endoscopy 2018; 50: 378-385 